University of Nebraska - Lincoln

DigitalCommons@University of Nebraska - Lincoln

$1-5-2004$

\title{
Water absorption and dielectric changes in crystalline poly(vinylidene fluoride-trifluoroethylene) copolymer films
}

\author{
P.A. Jacobson \\ University of Nebraska-Lincoln \\ Luis G. Rosa \\ University of Nebraska-Lincoln, luis.rosa13@upr.edu \\ Christina M. Othon \\ University of Nebraska-Lincoln, cothon@wesleyan.edu \\ Kristin L. Kraemer \\ University of Nebraska-Lincoln, kkraemer@unlserve.unl.edu
}

\section{A.V. Sorokin \\ University of Nebraska-Lincoln}

See next page for additional authors

Follow this and additional works at: https://digitalcommons.unl.edu/physicsdowben

Part of the Physics Commons

Jacobson, P.A.; Rosa, Luis G.; Othon, Christina M.; Kraemer, Kristin L.; Sorokin, A.V.; Ducharme, Stephen; and Dowben, Peter A., "Water absorption and dielectric changes in crystalline poly(vinylidene fluoridetrifluoroethylene) copolymer films" (2004). Peter Dowben Publications. 9.

https://digitalcommons.unl.edu/physicsdowben/9

This Article is brought to you for free and open access by the Research Papers in Physics and Astronomy at DigitalCommons@University of Nebraska - Lincoln. It has been accepted for inclusion in Peter Dowben Publications by an authorized administrator of DigitalCommons@University of Nebraska - Lincoln. 


\section{Authors}

P.A. Jacobson, Luis G. Rosa, Christina M. Othon, Kristin L. Kraemer, A.V. Sorokin, Stephen Ducharme, and Peter A. Dowben 


\title{
Water absorption and dielectric changes in crystalline poly(vinylidene fluoride-trifluoroethylene) copolymer films
}

\author{
P. A. Jacobson, Luis G. Rosa, C. M. Othon, Kristin L. Kraemer, A. V. Sorokin, Stephen \\ Ducharme, and P. A. Dowben ${ }^{\text {a) }}$ \\ Department of Physics and Astronomy, Behlen Laboratory of Physics, Center for Materials Research and \\ Analysis, University of Nebraska-Lincoln, Lincoln, Nebraska 68588-0111
}

(Received 25 September 2003; accepted 3 November 2003)

Crystalline Langmuir-Blodgett copolymer films of vinylidene fluoride with trifluoroethylene (70\%:30\% and 80\%:20\%) absorb water. Water absorption is accompanied by film swelling, as indicated by an increase in lattice spacing, sometimes by as much as $5 \%$. This water absorption, between 0 and $40^{\circ} \mathrm{C}$, is a result of intercalation or occupation of interstitial sites between the layers of the film, not just water molecules filling voids and defect sites alone. An increase in the film capacitance is observed, although the polymer chains retain all trans configuration of the ferroelectric phase. (C) 2004 American Institute of Physics. [DOI: 10.1063/1.1637127]

Adsorbate interactions on surfaces have a long and rich history. Water absorption studies on even hydrophobic polymers are necessary due to the application of polymers in biomedical applications and device electronics. ${ }^{1,2}$ The Teflon $^{\mathrm{TM}}$-like polymer polyvinylidene fluoride (PVDF) and its copolymers with trifluoroethylene $(\mathrm{TrFE})$ and tetrafluoroethylene are a useful system for the study of ferroelectricity ${ }^{3,4}$ and heteropolymer electronic devices. ${ }^{5}$ The fact that these materials are supposed to be largely insoluble in water does not mean there is a complete absence of interaction. Crystalline polymers like polytetrafluoroethylene ${ }^{6}$ and $\mathrm{PVDF}^{7-9}$ can absorb small amounts (a few percent by weight) of water, but this water is usually thought to be located in pores and amorphous regions of the polymer film. ${ }^{7}$

Ultrathin ferroelectric films of copolymers like $70 \%$ vinylidene fluoride with $30 \%$ trifluoroethylene, $\mathrm{P}(\mathrm{VDF}-\mathrm{TrFE}$ 70:30), can be fabricated by LB deposition, can produce films with thickness ranging from 1 monolayer (1 ML, 0.5 $\mathrm{nm})$ to over $500 \mathrm{ML} .{ }^{10}$ These films are of sufficient crystallinity and orientation that the induced polarization reversal (induced by the tip bias in scanning tunneling microscope) can be imaged. ${ }^{11}$ The bulk crystallinity has been confirmed by $x$-ray and neutron diffraction on films from 4 to $150 \mathrm{ML}$ thick. $^{12-14}$

Two types of samples were use to study dielectric anomalies due to water absorption. The capacitors used for the dielectric measurements were constructed by evaporating a $100 \mathrm{~nm}$ aluminum electrode on glass, fabricating the $\mathrm{P}($ VDF-TrFE 70:30) copolymer film by horizontal LB deposition, and evaporating a top electrode of $100 \mathrm{~nm}$ aluminum. The samples for the present study consisted of a 5 ML LB copolymer film with electrodes of $1 \mathrm{~mm}^{2}$ area, and $20 \mathrm{ML}$ films with an electrode area of $3 \mathrm{~mm}^{2}$. For $\mathrm{x}$-ray studies, 100 monolayer LB P(VDF-TrFE 80:20) samples were used, deposited, on $\mathrm{Si}(111)$ with $1 \mathrm{~cm}^{2}$ area. The sample capacitance was measured at $1 \mathrm{kHz}$ as a function of temperature $\left(+0.5^{\circ} \mathrm{C}\right)$ and relative humidity $( \pm 2 \%)$.

\footnotetext{
a) Author to whom correspondence should be addressed; electronic mail: pdowben@unlinfo.unl.edu
}

X-ray diffraction (XRD) studies in a water vapor ambient and in vacuum were undertaken to study environmental effects on the lattice constant of the well-ordered copolymer films of VDF with $\operatorname{TrFE}$ (70\%:30\% and 80\%:20\%), fabricated by LB deposition. A small stainless steel vacuum chamber, with a Mylar ${ }^{\mathrm{TM}}$ window largely transparent to the $\mathrm{x}$ rays, was built ${ }^{15}$ much like similar chambers described in the literature, ${ }^{16}$ and mounted in a Rigaku D/Max-B $\theta-2 \theta$ x-ray diffractometer. This allowed scans of $2 \theta$ through nearly $180^{\circ}$, and determination the lattice constant in the normal direction. The main Mylar ${ }^{\mathrm{TM}}$ contribution to the $\theta-2 \theta$ diffraction intensity was in the vicinity of $26^{\circ}$, well away from the $\mathrm{P}(\mathrm{VDF}-\mathrm{TrFE})$ copolymer film contributions near $20^{\circ}$ in the ferroelectric phase and $18^{\circ}-19^{\circ}$ in the paraelectric phase. ${ }^{10,12}$

Although water is not considered a standard solvent for $\mathrm{P}(\mathrm{VDF}-\mathrm{TrFE})$, the well-ordered $\mathrm{P}(\mathrm{VDF}-\mathrm{TrFE})$ copolymer films swell when immersed in water. For the films annealed in vacuum, there is an increase in the $\langle 110\rangle$ lattice interlayer spacing ranging from 4.35 to $4.45 \AA$ for the water free films to as much as $4.55 \AA$ with long exposure to water. This is seen in the XRD measurements shown in Fig. 1. Shown are the annealed film (a) and after contact with liquid water at room temperature for $50 \mathrm{~h}$ (b), $120 \mathrm{~h}$ (c), and $240 \mathrm{~h}$ (d). Even in contact with liquid water, the copolymer films may not reach equilibrium for hours or days. While the degree of lattice expansion varied considerably among samples, all exhibited the same trend: an increase in the $\langle 110\rangle$ layer by spacing by between 0.2 to $0.8 \AA$ after exposure to water or water vapor. A larger initial lattice constant, for the annealed film, leads to greater swelling (by as much as a $4 \%$ increase in lattice constant). For films with the smallest lattice constant, there is still some increase in lattice constant $(0.5 \%)$ and a decrease in the $\langle 110\rangle \mathrm{x}$-ray diffraction intensity. This trend is summarized in Fig. 2.

By gradually increasing the annealing temperature and then annealing for $3 \mathrm{~h}$ at $110^{\circ} \mathrm{C}$ the water was removed from $\mathrm{P}(\mathrm{VDF}-\mathrm{TrFE})$ thin films. After annealing the film, both the diffraction intensities and the original, film-specific lattice 


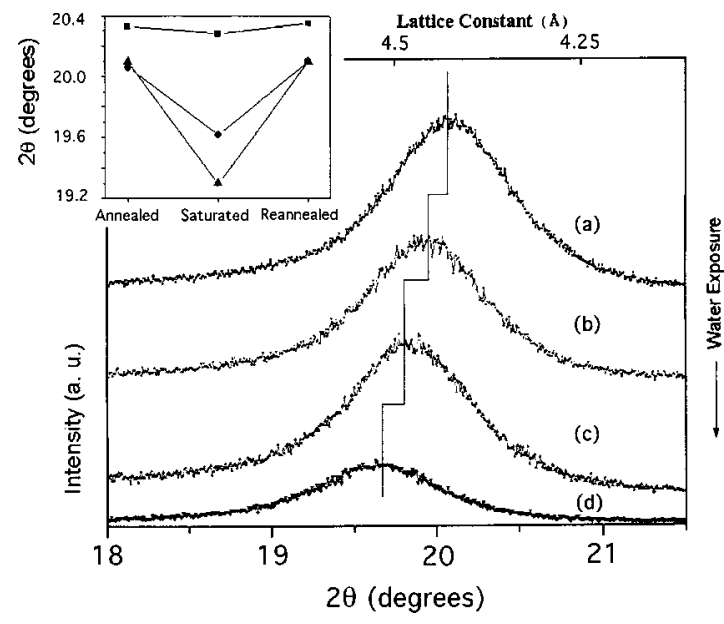

FIG. 1. Increase in the layer lattice spacing along the film normal for crystalline copolymer LB films of $80 \%$ VDF with $20 \%$ TrFE with water exposure. The $\theta-2 \theta$ XRD scans, recorded at room temperature, are shown for the water free film (a) and for increasing exposure to water (b, c, d). The film is nominally $100 \mathrm{ML}$ thick.

constant are recovered, as indicated by the inset to Fig. 1. Thus, water absorption is reversible and does not appear to lead to any permanent persistent changes to the P(VDFTrFE) thin films.

Although diffraction peak widths increase with increasing water absorption (Figs. 1 and 2), the increases are small compared to the dramatic changes in diffraction peak position. Such small increases in diffraction peak widths indicate that the water is largely adsorbed uniformly throughout the film, not just in the surface region. Furthermore, the diffraction peaks remain narrow and shift slowly over a period of many hours, indicating that uniform water concentration is rapidly established within the film and that absorption is limited by the interfaces. Because the fractional swelling is larger for films with the larger initial layer spacing, after the first annealing treatment, defects or the registry between crystal layers may play a role in the extent and rate at which water is absorbed, although the mechanism of water absorption cannot be inferred from the present data. In spite of dramatic changes with water absorption, the $\langle 110\rangle$ diffraction peak positions are inconsistent with the trans-gauche paraelectric phase ${ }^{10,12}$ of the $\mathrm{P}(\mathrm{VDF}-\mathrm{TrFE})$ thin film.

We have undertaken studies of the effect of humidity on the capacitance of $\mathrm{P}(\mathrm{VDF}-\mathrm{TrFE}$ 70:30) polymer thin-film samples. The sample capacitance increased with increased humidity, likely due to the absorption of water by the polymer film. The humidity effects are most evident in the capacitance while the temperature is varied from -20 to $60{ }^{\circ} \mathrm{C}$ (Fig. 3). In a dry nitrogen environment (curve 1, Fig. 3), the capacitance of the $5 \mathrm{ML}$ samples increased linearly with increasing temperature, following the increase in the bulk dielectric constant of the polymer. ${ }^{17}$ The same linear behavior was observed when the sample was in a $5 \mu$ Torr vacuum. When the chamber had significant humidity and the $5 \mathrm{ML}$ $\mathrm{P}(\mathrm{VDF}-\mathrm{TrFE})$ sample was precooled well below room temperature, the capacitance exhibited a large broad peak (sometimes more than one) from about 10 to $35^{\circ} \mathrm{C}$, as shown in curve 2, Fig. 3. We often observed condensation on the samples during measurements with high humidity, if the sample was kept below $10^{\circ} \mathrm{C}$ for a few minutes or more.

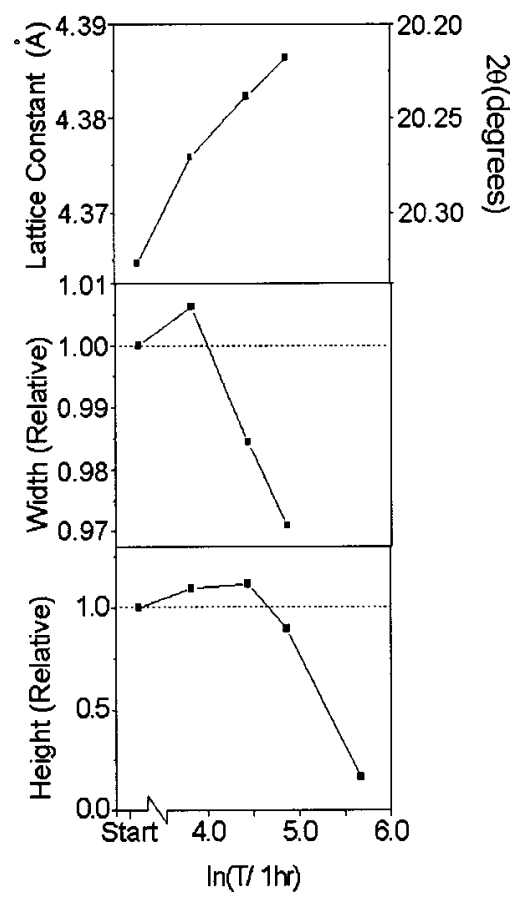

FIG. 2. The lattice constant, peak width and x-ray peak intensity as a function of water exposure, as abstracted from data on one of the best ordered 100 ML P(VDF-TrFE) copolymer LB thin films.

This could explain the broad peak(s) in the capacitance observed on heating. As the temperature is increased, the capacitance at first increases as the water infiltrates the film and then drops above $30^{\circ} \mathrm{C}$ as the water is evaporated. There was usually a small peak in the capacitance on cooling below room temperature (curve 2, Fig. 3). If the temperature change occurs in a humidity-controlled environment, then no dielectric anomaly occurs on heating or cooling, and there is no observed hysteresis in the change of capacitance with temperature in a 20 -ML-thick film at $40 \%$ relative humidity (curve 3, Fig. 3).

Since the heating and cooling experiments are far from equilibrium conditions, we conducted a series of capacitance measurements at constant temperature on a 20-ML-thick film, as the humidity was increased from 0 to $80 \%$ relative humidity at a rate of $1 \%$ relative humidity per minute and then decreased back to zero at the same rate (inset to Fig. 3). The capacitance increased at a rate of roughly $12.5 \mathrm{pF}$ per $1 \%$ increase in relative humidity, as seen in the data taken at both at 40 and $60^{\circ} \mathrm{C}$ (inset to Fig. 3). There was no significant hysteresis in the capacitance in these measurements, showing that the water could be repeatedly absorbed and removed, again consistent with the XRD results. Dynamic measurements show that the film capacitance, and presumably the water content, has a temperature-dependent time constant of several hours at room temperature.

The $\mathrm{dc}$ conductance of the film tracks the capacitance, ${ }^{18,19}$ indicating that the water is absorbed in the bulk of the film, and is not confined to the electrodes or interfaces. This is consistent with the results from the XRD measurements. Note that for samples in vacuum, dry nitrogen, and controlled humidity, no dielectric anomaly is seen in scans of capacitance versus temperature; the capacitance peaks (curve 2, Fig. 3) are a nonequilibrium effect connected with condensation. A similar increase of capacitance in the
AIP license or copyright, see http://apl.aip.org/apl/copyright.jsp 


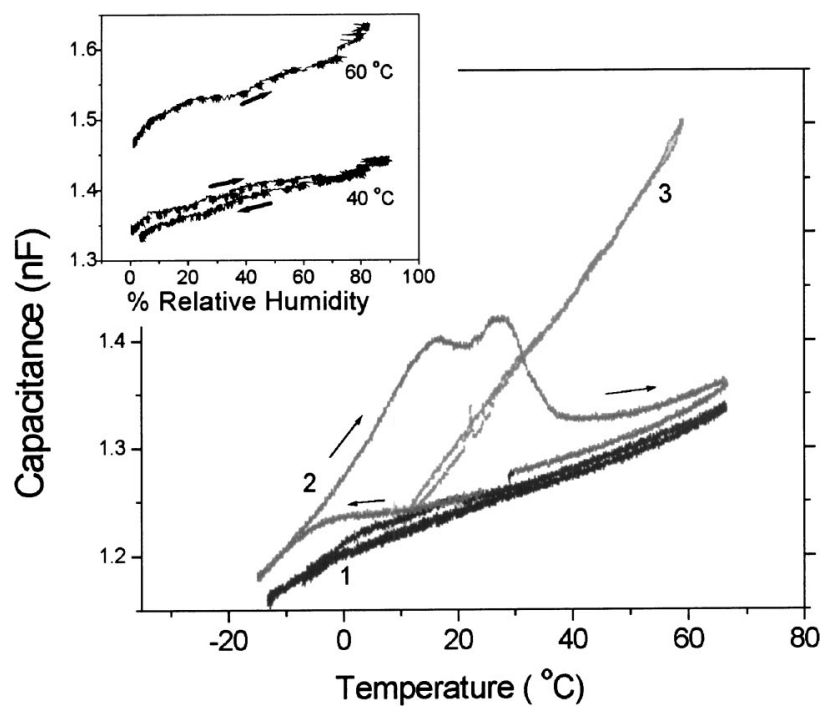

FIG. 3. Capacitance of the 5 and 20 ML P(VDF-TrFE 70:30) copolymer films under different ambient conditions. Inset: capacitance of a $20 \mathrm{ML}$ sample at constant temperature over a range of controlled humidity levels.

presence of water, was observed over the frequency range from $1 \mathrm{~Hz}$ to $10 \mathrm{kHz}$.

If we estimate the water concentration in the film from the capacitance data recorded for $40{ }^{\circ} \mathrm{C}$ (inset to Fig. 3) and assume that the water contribution to capacitance is proportional the bulk dielectric constant of $\sim 73$, we calculate that the water concentration in the film was approximately $1.4 \%$ by volume at $40{ }^{\circ} \mathrm{C}$ and $80 \%$ humidity. This value is much smaller than the $3 \%$ observed by gravimetric techniques in $\mathrm{PVDF}^{9}$ and suggested by the observed increase in lattice constant and profound loss in X-ray scattering peak intensity. The reason for the low estimate from the capacitance change could be due to dissociation or large barriers due to the rotation of the water molecules, or both. Both van der Waals and dipole-dipole interactions of water with the polymer could lead to water orientations that do not provide the full dielectric contribution expected from water to the capacitance.

Early measurements had shown a peak in capacitance as the sample was heated from -10 to $30^{\circ} \mathrm{C}$ in ambient conditions and attributed to a surface transition in the film. ${ }^{18-20}$ When the experiment was repeated in a vacuum, the capacitance remained linear, showing no peak. The present results show that the capacitance peak is correlated with chamber humidity. There is a surface "pseudo" ferroelectric phase transition, in the total absence of water, in the vicinity of $25^{\circ} \mathrm{C},{ }^{10,12,14,18-22}$ but we now know that this transition is not accompanied by a dielectric peak (curves 1 and 3, Fig. 3). The surface transition occurs under UHV conditions, it is manifest in the changes in the band structure, ${ }^{12,21}$ dipole ordering, ${ }^{18,21}$ and optical second-harmonic generation, ${ }^{22}$ and is not the consequence of water absorption.

Since water is accompanied by its own dipole moment, water absorption is expected, and indeed is observed, to increase the capacitance of $\mathrm{P}(\mathrm{VDF}-\mathrm{TrFE})$ as noted here, and of PVDF as noted elsewhere. ${ }^{8}$ Dielectric anomalies might be anticipated near the critical point of water due to ferroelectric contributions from the water itself, ${ }^{23,24}$ or interface polariza- tion contributions from the water ${ }^{25-28}$ induced by the surrounding PVDF-TrFE. The "anomaly" in the capacitance versus temperature that we have observed is probably dynamic and does not necessarily signify any water-related transition in the film. Nonetheless, the bulk dielectric and ferroelectric properties of $\mathrm{P}(\mathrm{VDF}-\mathrm{TrFE})$ copolymers must now be assessed in terms of the environment in which the measurements are undertaken and the water content.

Support from the Petroleum Research Fund, the NSF "QSPINS" MRSEC (DMR 0213808), and the Nebraska Research Initiative at the University of Nebraska is gratefully acknowledged. The authors thank A. N. Caruso for his comments on the manuscript.

${ }^{1}$ D. De Rossi, E. Stussi, and C. Domenici, in Ferroelectric Polymers, edited by H. S. Nalwa (Marcel Dekker, New York, 1995), p. 791; Medical Applications of Piezoelectric Polymers, edited by P. M. Galletti, D. E. Rossi, and A. S. DeReggi (Gordon and Breach, New York, 1988).

${ }^{2}$ The Applications of Ferroelectric Polymers, edited by T. T. Wang, J. M. Herbert, and A. M. Glass (Chapman and Hall, New York, 1988).

${ }^{3}$ A. J. Lovinger, Macromolecules 16, 1529 (1983).

${ }^{4}$ T. Furukawa, Phase Transitions 18, 143 (1989).

${ }^{5}$ B. Xu, Y. Ovchenkov, M. Bai, A. N. Caruso, A. V. Sorokin, S. Ducharme, B. Doudin, and P. A. Dowben, Appl. Phys. Lett. 81, 4281 (2002).

${ }^{6}$ M. A. Butler, R. J. Buss, and C. H. Seager, Appl. Phys. Lett. 59, 2817 (1991).

${ }^{7}$ Y. Saito, H. Kataoka, E. Quartarone, and P. Mustarelli, J. Phys. Chem. B 106, 7200 (2002)

${ }^{8}$ A. S. Castela and A. M. Simoes, Corros. Sci. 45, 1631 (2003).

${ }^{9}$ A. S. Castela and A. M. Simoes, Corros. Sci. 45, 1647 (2002).

${ }^{10}$ S. Ducharme, S. P. Palto, V. M. Fridkin, and L. M. Blinov, in Ferroelectric and Dielectric Films, Handbook of Thin Film Materials Vol. 3, edited by H. S. Nalwa (Academic, 2002), Chap. 11

${ }^{11}$ H. Qu, W. Yao, T. Garcia, J. Zhang, A. V. Sorokin, S. Ducharme, P. A. Dowben, and V. M. Fridkin, Appl. Phys. Lett. 82, 4322 (2003).

${ }^{12}$ J. Choi, C. N. Borca, P. A. Dowben, A. Bune, M. Poulsen, S. Pebley, S. Adenwalla, S. Ducharme, L. Robertson, V. M. Fridkin, S. P. Palto, N. Petukhova, and S. G. Yudin, Phys. Rev. B 61, 5760 (2000).

${ }^{13}$ C. N. Borca, J. Choi, S. Adenwalla, S. Ducharme, P. A. Dowben, L. Robertson, V. M. Fridkin, S. P. Palto, and N. Petukhova, Appl. Phys. Lett. 74, 347 (1999).

${ }^{14}$ C. N. Borca, S. Adenwalla, J. Choi, P. T. Sprunger, S. Ducharme, L. Robertson, S. P. Palto, J. Liu, M. Poulsen, V. M. Fridkin, H. You, and P. A. Dowben, Phys. Rev. Lett. 83, 4562 (1999).

${ }^{15}$ P. A. Jacobson, L. Rosa, and P. A. Dowben (unpublished).

${ }^{16}$ W. J. Rink, H. G. Mathias, and J. B. Schlenoff, J. Appl. Crystallogr. 27, 666 (1994).

${ }^{17}$ T. Yagi, M. Tatemoto, and J. Sako, Polym. J. (Tokyo) 12, 209 (1980).

${ }^{18}$ J. Choi, P. A. Dowben, S. Pebley, A. Bune, S. Ducharme, V. M. Fridkin, S. P. Palto, and N. Petukhova, Phys. Rev. Lett. 80, 1328 (1998).

${ }^{19}$ L. M. Blinov, V. M. Fridkin, S. P. Palto, A. V. Bune, P. A. Dowben, and S. Ducharme, Usp. Fiz. Nauk 170, 247 (2000); Phys. Usp. 43, 243 (2000) [English edition].

${ }^{20}$ A. V. Bune, V. M. Fridkin, S. Ducharme, L. M. Blinov, S. P. Palto, A. V. Sorokin, S. G. Yudin, and A. Zlatkin, Nature (London) 391, 874 (1998).

${ }^{21}$ J. Choi, P. A. Dowben, S. Ducharme, V. M. Fridkin, S. P. Palto, N. Petukhova, and S. G. Yudin, Phys. Lett. A 249, 505 (1998).

${ }^{22}$ O. A. Aktsipetrov, T. V. Misuryaev, T. V. Murzina, L. M. Blinov, V. M. Fridkin, and S. P. Palto, Opt. Lett. 25, 411 (2000).

${ }^{23}$ M. J. Iedema, M. J. Dresser, D. L. Doering, J. B. Rowland, W. P. Hess, A. A. Tsekouras, and J. P. Cowin, J. Phys. Chem. B 102, 9203 (1998).

${ }^{24}$ O. Dengel, U. Eckener, H. Plitz, and N. Riehl, Phys. Lett. 9, 291 (1964).

${ }^{25}$ K. Kutzner, Thin Solid Films 14, 49 (1972).

${ }^{26}$ L. Onsager, D. L. Staebler, and S. Mascarenhas, J. Chem. Phys. 68, 3823 (1978).

${ }^{27}$ X. C. Su, L. Lianos, Y. R. Shen, and G. A. Somorjai, Phys. Rev. Lett. 80, 1533 (1998)

${ }^{28}$ X. L. Zhao, S. W. Ong, and K. B. Eisenthal, Chem. Phys. Lett. 202, 513 (1993) 